Sharif University of Technology
Scientia Iranica
SCIENTIA
I RAN I CA

\title{
Numerical study of an innovative SMA based beam-column connection in reducing the seismic response of steel MRF structures
}

\author{
F.R. Rofooei ${ }^{a, *}$ and A. Yadegari Farzaneh ${ }^{b}$ \\ a. Department of Civil Engineering, Sharif University of Technology, Tehran, Iran. \\ b. Building and Housing Research Center, Tehran, Iran. \\ Received 7 September 2015; accepted 5 January 2016
}

\section{KEYWORDS}

Shape Memory Alloy (SMA);

Vibration control; End plate connection; Superelastic effect; Seismic behavior.

\begin{abstract}
During recent years, Shape Memory Alloys (SMAs) have been effectively used to control the seismic response of structural systems. Recovering the residual strains upon unloading (super-elasticity) or by heating (shape memory effect) is the main characteristic of SMA materials. This paper explores the efficiency of a proposed application of steel \& SMA bolts in improving the seismic behavior of connections in steel Moment Resisting Frame (MRF) structures. A new semi-rigid, end-plate, beamcolumn connection is introduced, which is based on parallel application of steel and austenite-phase SMA bolts. A number of 3-D steel MRF structural models with different numbers of stories and mass eccentricities are considered. These structural models that are designed by employing the conventional rigid and the proposed semi-rigid connections are subjected to bi-directional earthquake records that have been scaled according to ASCE7-05 procedure. Extensive nonlinear dynamic time history analyses are conducted to evaluate the efficiency of the steel \& SMA based connections in enhancing the seismic performance of the structural models. The obtained results indicate that the proposed steel-SMA connection is highly promising and can efficiently reduce the seismic response parameters of the structural systems. Steel bolts of the end-plate connections contribute both to shear force transfer (from beam to column) and dissipation of the input seismic energy through hysteresis behavior. On the other hand, parallel application of steel and SMA bolts in the connections reduces the story drifts as well as the induced forces in the structural elements while decreasing the permanent story displacements. The main goal obtained is to keep the beams away from the formation of plastic deformation. OpenSees platform is used for generating the structural models and performing the numerical analyses.
\end{abstract}

(C) 2016 Sharif University of Technology. All rights reserved.

\section{Introduction}

Heavy structural damages caused by strong ground motions have persuaded the researchers to think of some

\footnotetext{
*. Corresponding author. Tel.: +982144624971;

Fax.: +982188799135

E-mail addresses: rofooei@sharif.edu (F.R. Rofooei);

abbas.yadegari@gmail.com (A. YadegariFarzaneh)
}

precautionary measures to safeguard the buildings and their equipment against the expected seismic hazards. In this regard, the beam-column connections are of extreme importance in any MRF structural systems for maintaining the stability of the structural system while dissipating the input energy through their hysteresis behavior. The conventional welded steel MRF structures have suffered substantial damages in the beamto-column connections during the 1994 Northridge and 
the 1995 Kobe earthquake episodes [1,2]. Different types of failure occurred in the traditional connections of steel MRF structures during recent earthquakes have led the researchers to search for alternative solutions to the problem [3-6].

A number of follow-up studies were mainly focused on shifting the potential location of plastic hinges away from the column face. In this way, the improved ductility of the connection would be associated with the formation of plastic hinges or local buckling in the connected beam. These permanent deformations necessitate a restoring process to be undertaken for the damaged elements. The extended end-plate moment connection types are equally subjected to these kinds of problems under cyclic loadings [7]. However, in the end-plate connection type, the existing repairable connection gap provides the possibility of performing a variety of modifications to improve its performance.

On the other hand, various supplemental damping devices have been introduced to increase the energydissipating capacity of the structural systems, while reducing their seismic demands. More specifically, the Shape Memory Alloys (SMA) have enjoyed the attention of many researchers and engineers in recent years due to their unique features such as superelasticity and shape memory effect that make them attractive for vibration suppression of structural systems. According to recent studies, SMAs could be used in different ways to improve the seismic behavior of structural systems [8-11], including those with endplate connections. [12]. A numerical study on bolted end-plate connections using shape memory alloys indicate that the deformations of the connections under extreme loading are recoverable upon unloading [13]. Moreover, in contrast to the conventional bolted moment resisting connections, the SMA based connections demonstrate moderate energy-dissipating capacity due to the superelastic effect of the SMA bolts in each cycle. However, the total energy dissipated through repetitive loading-unloading phases would be much higher if high resistance to stiffness degradation is maintained.

An experimental study on t-stub connections equipped with the superelastic SMA fasteners indicates that their energy dissipating capacity is higher than the t-stub connections with steel fastener for the particular stress level under consideration [14]. The previously described features of the SMAs could improve the behavior of the flexible end-plate connection through both re-centering capacity and high damping ability. Ocel et al. proposed and tested a special steel connection consisting of four SMA bars in the martensitic phase, which played the role of a moment transfer mechanism that were used at the top and bottom flanges of a beam in its connection to the column [15]. As the experimental results indicated, the proposed connection showed sufficient flexibility and high damping capacity.
Moreover, the hysteresis loops of the SMA bars up to $4 \%$-drift cycles were identical without any sign of strength and stiffness degradation or fatigue. This implies that these hybrid connections could be re-used in the following seismic events if the tendons are appropriately heated to initiate the shape memory effect. $\mathrm{Ma}$ et al. investigated a new connection consisting of an extended end-plate with SMA bolts, continuity plates, beam flange ribs, and web stiffeners [16]. The SMA based connection increases load capacity without any sign of local buckling in the connected beam during loading process. Moreover, a considerable amount of the induced curvature of the SMA based connections is recoverable upon unloading.

SMAs can sustain large strains and recover upon unloading in Austenite Phase (super-elasticity) or by heating in Martensite Phase (Shape Memory Effect) [17-19]. Moreover, they can introduce a moderate level of damping and considerable energy-dissipating capacity due to their stable mechanical behavior $[17,20$ $22]$.

The phase transformation of SMA materials, as shown in Figure 1, is specified by its stress, strain, and temperature states. In zero stress level, and $T<M_{f}$, a fully Martensite phase would be present, while for $T>A_{f}$, the SMA material would change to a complete austenitic phase. The super-elasticity feature is achieved by the direct phase transformation of SMA materials from austenite to martensite through inducing stress, providing $T>A_{f}$, and from a reverse martensite to austenite through removing stress. The Shape Memory Effect (SME) feature is achieved in two phases. First, under the stress at $T<M_{f}$, the SMA starts to change to detwinned austenite phase from its twinned martensite state. Then, upon a stress release, the twinned martensite phase would form. In the second phase, applying heat would lead to generation of the undeformed shape in austenite phase, as shown in Figure $1[15,17,22]$.

Superelastic SMAs have several characteristics that qualify them to be used as a means for vibration control and retrofit of structural systems. Some of their unique characteristics include large elastic

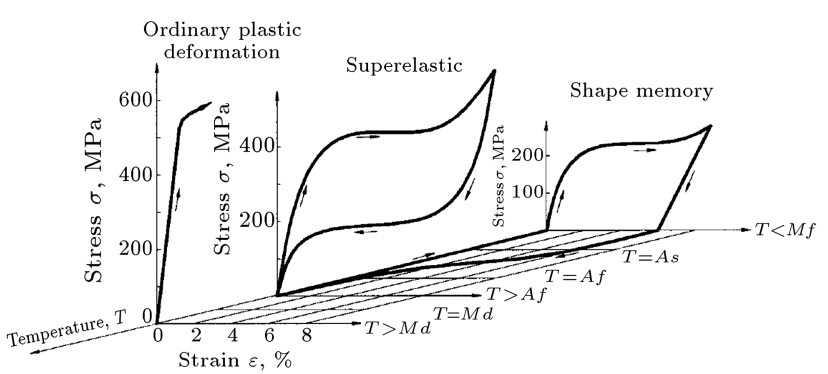

Figure 1. The stress-strain-temperature behavior of NiTi shape memory alloys (Reginald DesRoches et al. 2004 [18]). 
and recoverable inelastic strain levels, availability of hysteresis damping in post-yield state besides the re-centering capacity, sustaining many cycles before fatigue happens, and providing a stress plateau, thus preventing strain hardening $[17,19,22,23]$. DesRoches et al. reported some experimental summaries of the mechanical properties of Ni-Ti shape memory alloys [18]. In austenite state, their Young modulus and yield strength are reported to be $30-83 \mathrm{GPa}$ and 195-690 $\mathrm{MPa}$, respectively. Also, their recoverable elongation can be assumed to be $8 \%$ at the most. In recent applications that are mostly related to SMA wires and thin SMA tendons, the effects of strain rate and specimen size on residual strain, loading and unloading plateau stress levels, and equivalent viscous damping ratios of SMAs have been investigated. Auricchio et al. have performed a numerical and experimental investigation to identify the damping properties of SMAs and create a comprehensive mathematical model suitable for studying the dependence of the stressstrain relationship on the loading-unloading rate [24]. The advantages of using SMA braces in a typical steel frame were studied by McCormick et al. [21]. Their results show that the SMA braces improve the response of the braced frames.

In the present work, following a previous work conducted by Rofooei and Farhidzadeh, a new endplate beam-column connection consisting of steel \& SMA bolts is proposed to reduce the seismic-induced response of steel MRF structures [12]. In this study, influence of using both steel ST-37 and austenite-phase Ni-Ti SMA bolts in a parallel manner, the dissipated energy per cycle, and the re-centering capacity of the proposed connection are investigated. In addition, sensitivity analyses are performed to evaluate the effect of different parameters on the performance of the proposed steel-SMA end-plate connection.

\section{Connection design procedure}

As mentioned earlier, one of the recent applications of SMAs in structural systems has been in the endplate, beam-to-column connections by using both SMA and steel bolts in steel MRF. In the present work, an extended end-plate, semi-rigid connection is introduced using a number of SMA bolts along with steel bolts that are placed at the farthest level away from the neutral

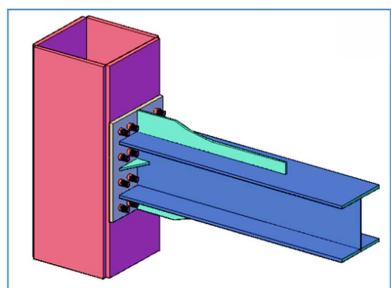

(a)

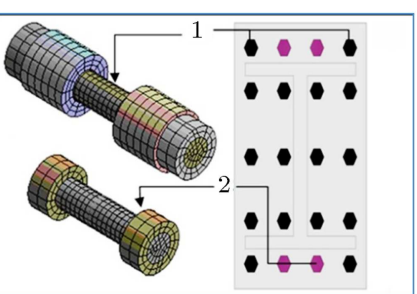

(b)
Figure 2. The proposed connection: (a) The beam connected to box column using the proposed end-plate connection equipped with steel \& SMA bolts; and (b) steel bolts with elongating washers (1) and SMA bolts (2).

axis of the connection face to provide a higher energydissipating capacity based on parallel performance of SMA and steel bolts.

The proposed connection, which is a modified version of Ma's model [13], is schematically shown in Figure 2. To create enough moment resisting capacity, an adequate number of steel bolts are placed at the distance between the previously mentioned SMA level and the neutral axis of connection face. Moreover, an adequate number of steel bolts can be used at the neutral axis of the connection face to create enough shear-resisting capacity. Also, some elongating bolt washers are used in steel bolts to equalize the axial stiffness of the SMA and steel bolts located at the same distance from the end-plate neutral axis.

As a result, under a unit induced rotation in the connection face, the amount of strain in SMA bolts becomes larger than that of the steel bolts. This approach leads to a greater contribution of SMA bolts in dissipating the input seismic energy to the structural system by formation of larger hysteresis loops. The properties of superelastic SMA material, shown in Figure 3, are listed in Table 1. The structural steel material (st-37) is used to model the steel bolts with $E=2.038 e 6 \frac{\mathrm{kg}}{\mathrm{cm}^{2}}$. Furthermore, Figure 3 schematically shows the hysteresis behavior of SMA as well as its model in OpenSees program.

\section{Structural models and selected ground motions}

A comprehensive study is carried out on the effectiveness of the simultaneous application of SMA and steel bolts in order to modify the previously proposed end-

Table 1. Mechanical properties of superelastic SMA (Hongwei Ma et al., 2008) [13].

\begin{tabular}{cl}
\hline Stress induced martensite transformation & Reverse phase transformation \\
\hline Starting stress $\sigma_{s}^{A S}: 375 \mathrm{MPa}$ & Starting stress $\sigma_{s}^{S A}: 208 \mathrm{MPa}$ \\
Final stress $\sigma_{f}^{A S}: 430 \mathrm{MPa}$ & Final stress $\sigma_{f}^{S A}: 138 \mathrm{MPa}$ \\
\hline \multicolumn{2}{c}{ Maximum recoverable strain $\bar{\varepsilon}_{L}: 0.09$} \\
Young modulus $E_{0}: 27.58 \mathrm{GPa}$ \\
\hline
\end{tabular}




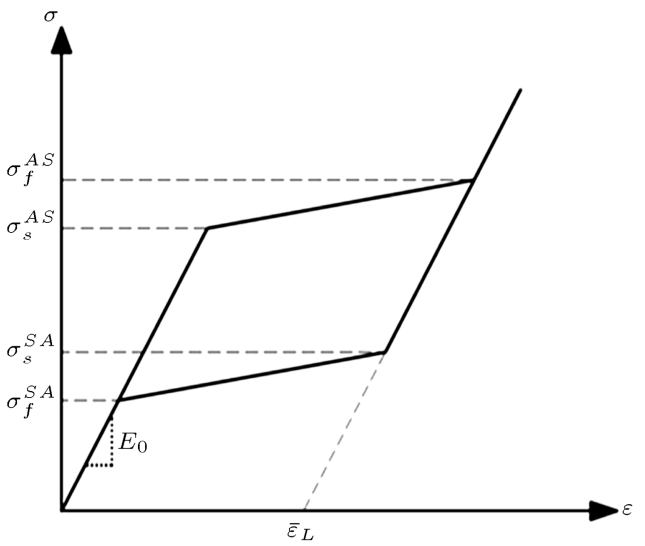

(a)

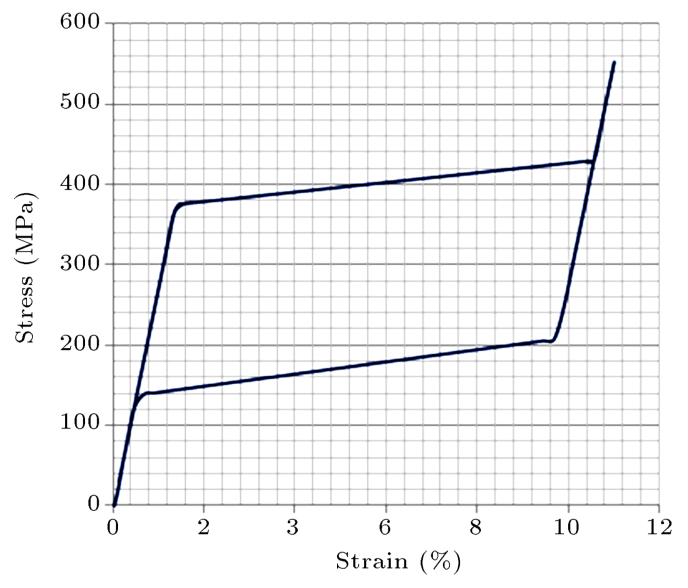

(b)

Figure 3. (a) Schematic hysteresis behavior of SMA. (b) The considered hysteresis behavior of SMA in OpenSees program.

plate connection. As the obtained results indicate, using SMA material in parallel with steel bolts increases the dissipated energy in comparison to the case without parallel SMA material [25]. Defining $R_{1}$ as the ratio of the cross sectional areas of the SMA and steel bolts:

$$
R_{1}=\frac{A_{\mathrm{SMA}}}{A_{\text {Steel }}}
$$

a parametric study is conducted to see its effect on the performance of the SMA material in reducing the response of the structural systems. A number of 3-D, 3-, 6-, 9-, and 12-story steel MRF structural models, located in California on soil type $\mathrm{C}$ with $0,5 \%, 10 \%$, and $15 \%$ mass eccentricities, are designed using the ASCE7-05 and AISC-LRFD99 Codes. All structural models contain 3 bays, with spans of 5 meters along $x$ and $y$ directions and 3.2 meters of story height. The 2 way concrete slab is assumed as gravity floor system behaving as a rigid diaphragm. The dead and live loads are considered as $600 \mathrm{~kg} / \mathrm{m}^{2}$ and $240 \mathrm{~kg} / \mathrm{m}^{2}$, respectively. All beam-column connections in the considered structural models are modeled using the details shown in Figure 2. Also, $W$ and box sections are used in the design of the beam and column elements, respectively, in all models.

The conventional direct rigid beam-to-column connections (DRCs) as well as the proposed connections with $70 \%, 80 \%, 90 \%$, and $100 \%$ rigidities are assumed for the parametric study. In all proposed connections, the design procedure is based on ultimate plastic capacity of connecting beam. Cross section area, distance of bolts from neutral axes, and number of bolts are the variables to achieve the demanded plastic moment capacity. Based on the limited parametric study conducted by the authors, the ratio $R_{1}=$ 2 for the SMA and steel bolts placed in the end plate was found to be optimal. All SMA bolts are presumably preloaded to have a preloading stress of
138Mpa. Preloading the SMA bolts increases the absorbed hysteresis energy as well as their re-centering capacity.

Using elongating washers around steel bolts placed in farthest distance from end-plate neutral axis is another tool to induce larger strains in SMA bolts and to better utilize SMA super-elasticity feature. This concept is observable by considering a unit rotation in the connection face. In this state, all the SMAs and steel bolts placed in the same axes experience equal elongations. Therefore, using half-length SMA bolts together with the steel bolts in the same row will double the stain in the SMA bolts in comparison to the steel bolts. On the other hand, the utilized weak beam and strong column concept used in preparation of the structural models assures the formation of any possible plastic hinges in beams.

The rigidity of the connections can be evaluated using the Rigidity Index (RI), defined as:

$$
\mathrm{RI}=\frac{\text { Plastic moment capacity of connection }}{\text { Plastic moment capacity of beam }} \text {. }
$$

The OpenSees platform is used for preparation of the structural models and performing the dynamic non-linear analyses. The hysteretic characteristics of the SMA and steel material were appropriately taken into account using the capabilities of the OpenSees platform.

Seven pairs of appropriate earthquake components recorded on site soil $\mathrm{C}$ are selected and scaled using the ASCE7-05 approach. Important features of the earthquake records are presented in Table 2. All the presented results, obtained from the nonlinear time history dynamic analyses, are the average results of 7 records. Also, all the considered eccentricities for the structural models as well as the input earthquake records are bi-directional. 
Table 2. Important features of the selected earthquake records for this study.

\begin{tabular}{llcccc}
\hline \multicolumn{1}{c}{ Earthquake } & Station & Magnitude & $\boldsymbol{P G \boldsymbol { A } _ { 1 } ( \mathrm { g } )}$ & $\boldsymbol{P G \boldsymbol { A } _ { 2 }}(\mathrm{g})$ & Soil type \\
\hline Loma Prieta & Capitola & 6.93 & 0.529 & 0.443 & $\mathrm{C}$ \\
Imperial Valley & Bonds Corner & 6.53 & 0.775 & 0.588 & $\mathrm{C}$ \\
Morgan Hill & Gilroy Array \#4 & 6.19 & 0.348 & 0.224 & $\mathrm{C}$ \\
Kobe, Japan & Takarazu & 6.9 & 0.694 & 0.693 & $\mathrm{C}$ \\
Northridge & Sylmar - Hospital & 6.69 & 0.843 & 0.604 & $\mathrm{C}$ \\
Duzce, Turkey & Bolu & 7.14 & 0.822 & 0.728 & $\mathrm{C}$ \\
Cape Mendocino & Rio Dell Overpass - FF & 7.01 & 0.549 & 0.385 & $\mathrm{C}$ \\
\hline
\end{tabular}
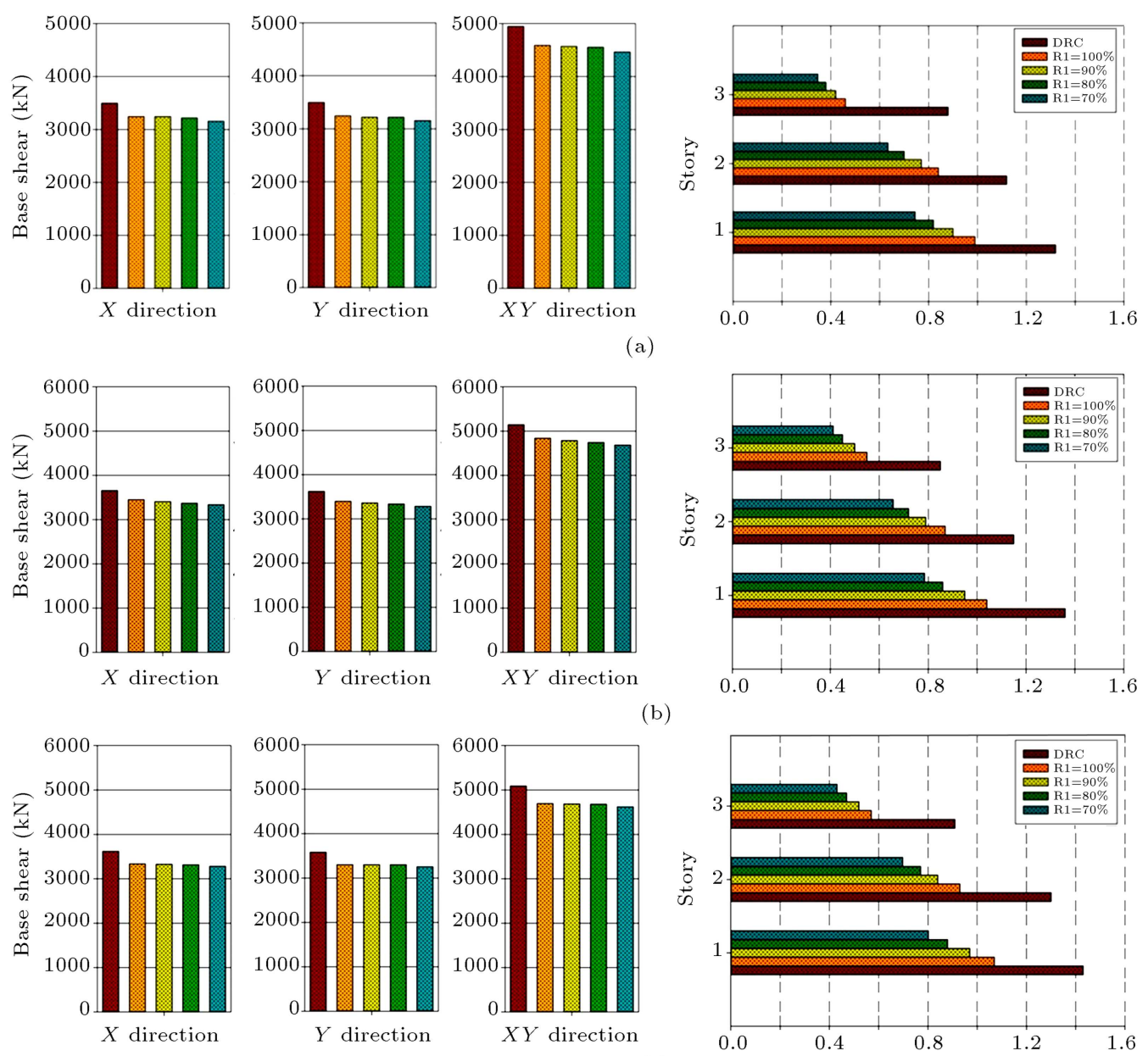

(c)

Figure 4. The maximum base shear force (left) and maximum ductility demand of beams (right) of the 3-story building model with (a) no eccentricity, (b) $5 \%$ eccentricity, and (c) $15 \%$ eccentricity.

\section{Results}

\subsection{Structural members' force and deformation demand}

Defining the maximum Flexural Demand Ratio (FDR) as:

$$
\mathrm{FDR}=\frac{\theta_{u}}{\theta_{y}}
$$

in which $\theta_{u}$ is the maximum induced rotation at the edge of beam and $\theta_{y}$ is the corresponding rotation at the beginning of yielding in the farthest fiber of beam, the maximum base shear forces and maximum FDR of beams (the maximum value on each floor) are presented in Figures 4 to 7 . These results are for both conventional direct rigid beam to column connections (DRC) and paralleled application of the steel and SMA bolts based end-plate connections for various RIs. For each story, the base shear forces along $x$ and $y$ directions and their SRSS combination 

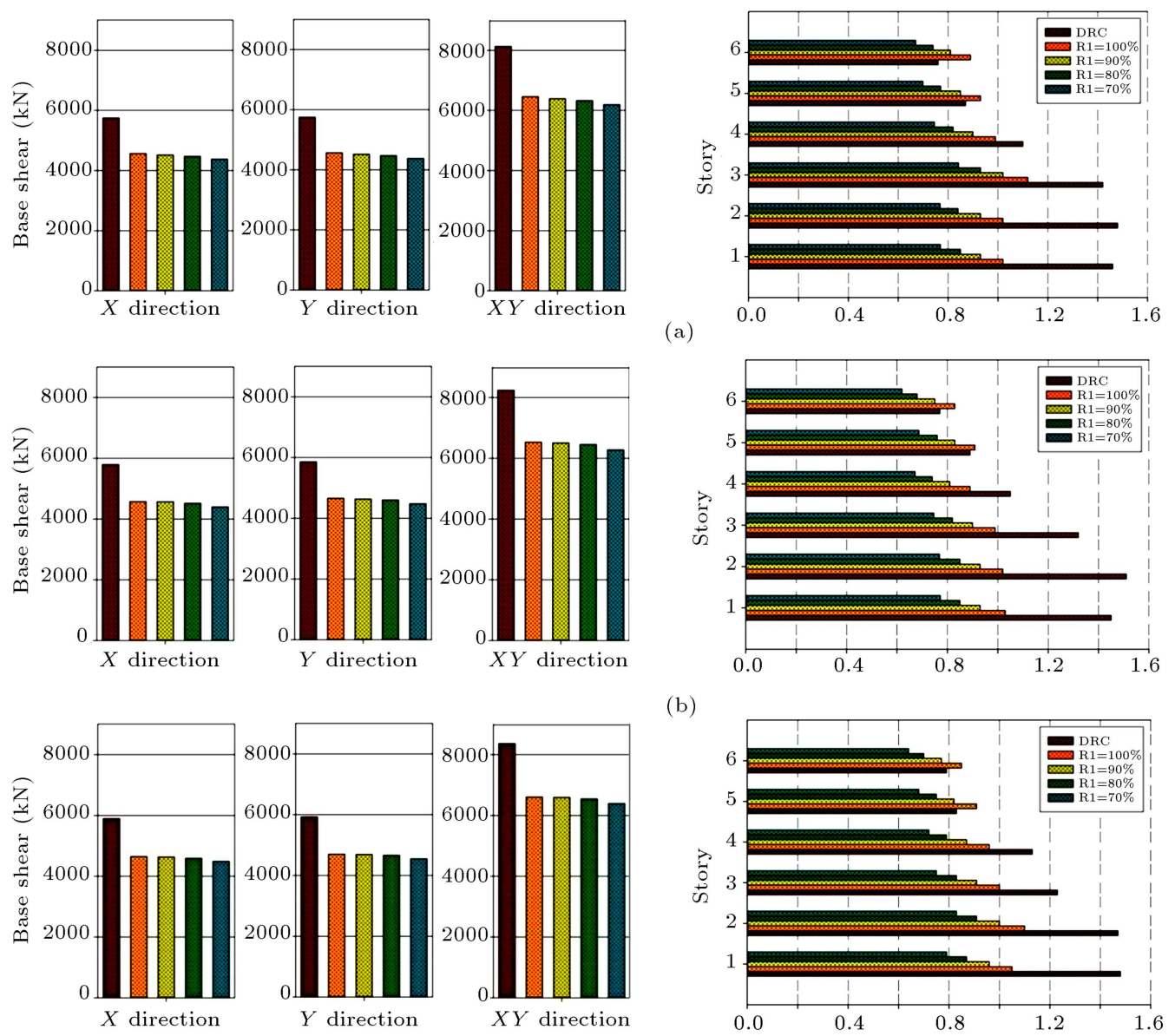

(b)

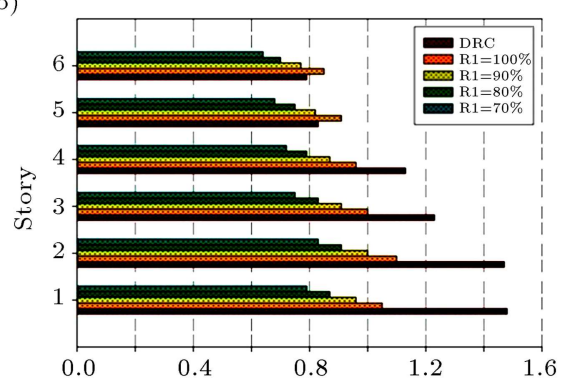

(c)

Figure 5. The maximum base shear force (left) and maximum ductility demand of beams (right) of the 6-story building model with (a) no eccentricity, (b) $5 \%$ eccentricity, and (c) $15 \%$ eccentricity.

(named $x y$ direction) are presented. Due to limited space, the obtained results of structural model with $10 \%$ eccentricity are not presented here.

According to the obtained results, one can observe that the base shear force in all of the considered structural models having different eccentricities decreases due to performance of the proposed steel-SMA connections with different RI values. In the 3 -story structural models, utilizing the proposed connections causes $6 \%$ $11 \%$ reduction in the base shear force depending on different RI values. Increasing the eccentricity slightly reduces the effect of the proposed connections. Using this connection in 6-story structural models is also effective in reducing the base shear forces by $19 \%-26 \%$.

In the 9-story structural models, depending again on different RI values and eccentricities, there is $14 \%$ to $25 \%$ reduction in the base shear forces. The decrease in 12-story structural models is around $11 \%$ to $20 \%$. In 9- and 12-story structural models, a change in the eccentricity causes a more tangible effect on the connection performance in reducing the base shear forces. It can be concluded from base shear forces that the connections demonstrate a desirable performance in damping the absorbed energy and eventually cause a lower force demand on the structural members. The decline in base shear force usually leads to a reduction in column force demand in moment resisting frames. It is important to notice that we are also assured of the desirable behavior of the beams in keeping them from formation of plastic hinges.

Using the proposed connections, the beam curvature demands have been effectively reduced in most cases. In this regard, the steel-SMA connection performed up to the expectation in reducing the deformation demands in beams. In the 3-story structural models, noting that the shear behavior is the governing one, deviation from the corresponding curvature of yielding is lower in conventional connections. In the worst-case scenario, there is a $37 \%$ deviation from corresponding curvature of yielding. The FDR values for the 3-story structural models having the proposed connections with different RI values are lower than one, except for the structural model with $\mathrm{RI}=100 \%$, for which there is a nearly 6 -percent deviation from $\theta_{y}$. In the 6-story structural models having conventional connections, only for the structural model with $\mathrm{RI}=100 \%$ 

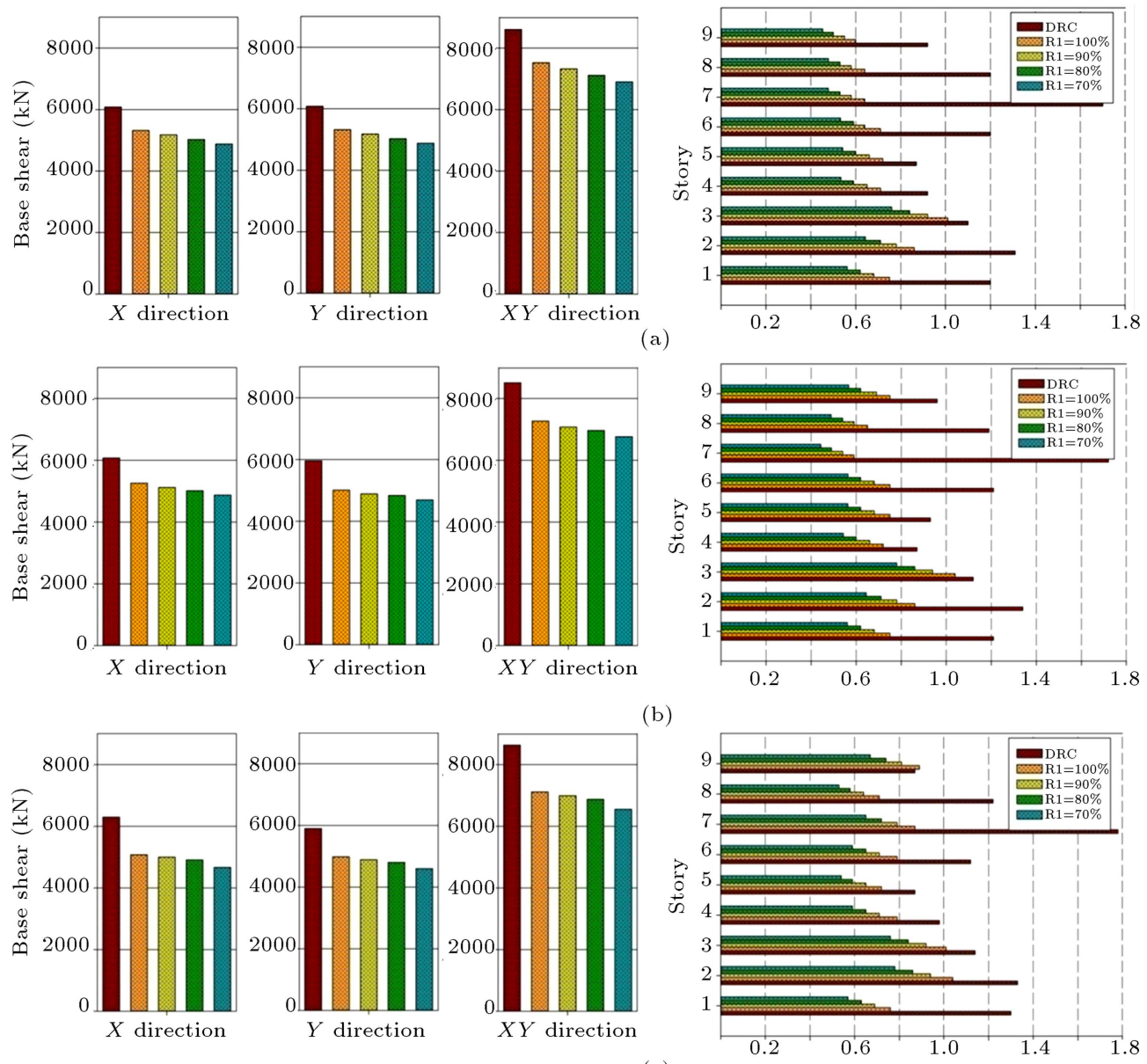

Figure 6. The maximum base shear force (left) and maximum ductility demand of beams (right) of the 9-story building model with (a) no eccentricity, (b) $5 \%$ eccentricity, and (c) $15 \%$ eccentricity.

and $90 \%$ eccentricities, slight deviation from $\theta_{y}$ has been recorded. The results obtained for 9 - and $12-$ story structural models and the proposed connection also demonstrate a very desirable performance in terms of deviation from $\theta_{y}$.

One should observe that no significant increase in the natural periods of the structural models is produced upon utilizing semi-rigid connections compared to structural models having conventional connections. However, based on studies conducted by the authors on the same structural models having the proposed connections of $\mathrm{Ma}$ et al. [13], there is $60 \%$ baseshear decrease along with an increase of almost 3 times in period values as well as 2 times deviation from maximum drift code limits. This increase in the period and the results obtained from the pushover analyses showed that the performance of the structural models having SMA based connections of Ma et al. [13] was not desirable with regard to the maximum story displacement and drifts. These defects are predicted to be more acute in taller buildings. In Table 3 , the results of a comparative study are presented on structural models equipped with the proposed steel-
SMA connection and one with connections based on SMA bolts only. In SMA based connection cases, usage of SMA bolts is increased to achieve a comparable condition considering the fundamental period of structural models. In these cases, usage of SMA materials is about 2.5 times that of the proposed connection cases.

\subsection{Inter-story drifts}

The primary purpose of examining story drifts is to satisfy ASCE7-05 code limitations. In fact, the purpose is not to reduce story drifts by means of the proposed connections. It seems reasonable to predict that using the proposed semi-rigid steel-SMA connections brings about an increase in story drifts. It was observed in Section 4.1 that a base shear decline and a desirable beam behavior were achieved in the structural models equipped with the proposed connections. However, these achievements are useful if the drift values are limited only to the code limitations. According to ASCE7-05 specifications, and noting the characteristics of the structural models, the allowable maximum drifts obtained from a nonlinear time history analysis $(\mathrm{NLTH})$ should not be more than 1.25 times the drift 


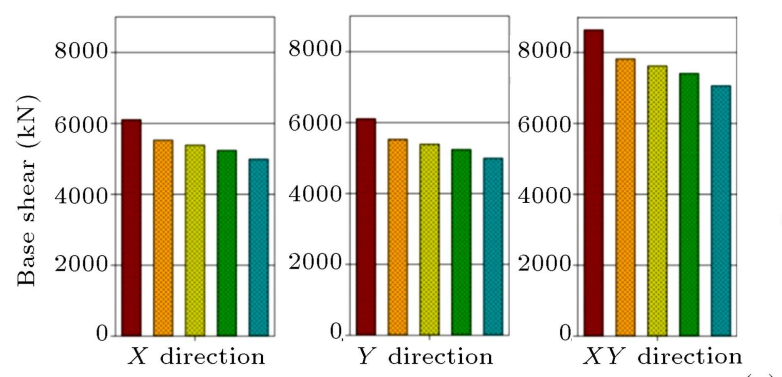

(a)
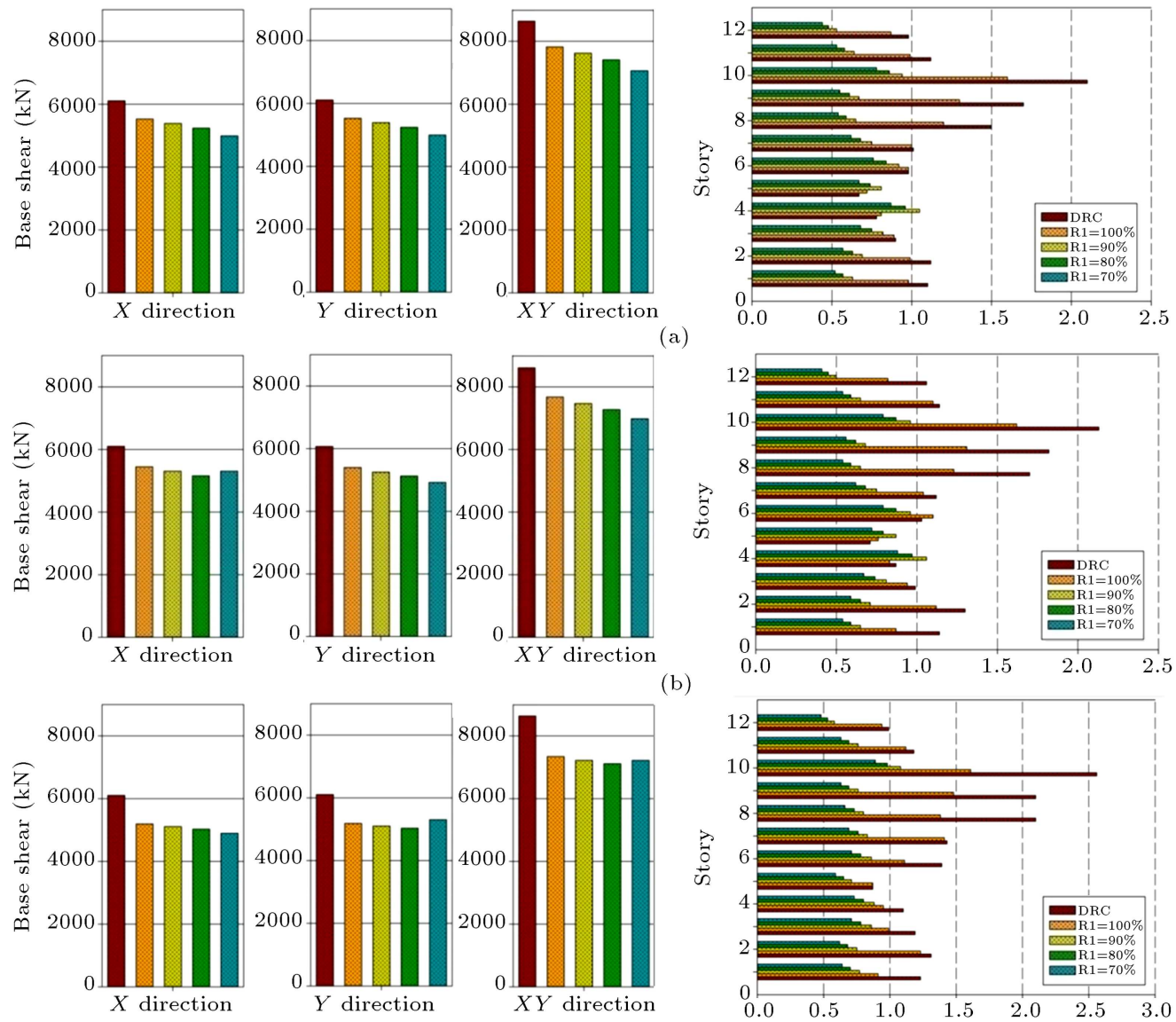

(c)

Figure 7. The maximum base shear force (left) and the maximum ductility demand of beams (right) of the 12-story building model with (a) no eccentricity, (b) $5 \%$ eccentricity, and (c) $15 \%$ eccentricity.

Table 3. Comparative study results of structural models equipped with the proposed steel-SMA connection and SMA alone based connection.

\begin{tabular}{|c|c|c|c|c|c|c|c|c|c|c|c|c|c|c|}
\hline \multirow{4}{*}{$\begin{array}{c}\text { Structural } \\
\text { models }\end{array}$} & \multicolumn{14}{|c|}{ Connection type } \\
\hline & \multirow{2}{*}{\multicolumn{2}{|c|}{$\frac{\text { Traditional }}{\text { DRC }}$}} & \multicolumn{8}{|c|}{ Proposed steel-SMA connection } & \multicolumn{4}{|c|}{ SMA alone based connection } \\
\hline & & & \multicolumn{2}{|c|}{$\mathrm{RI}=\mathbf{7 0 \%}$} & \multicolumn{2}{|c|}{$\mathrm{RI}=\mathbf{8 0 \%}$} & \multicolumn{2}{|c|}{$\mathbf{R I}=\mathbf{9 0 \%}$} & \multicolumn{2}{|c|}{$\mathrm{RI}=\mathbf{1 0 0 \%}$} & \multicolumn{2}{|c|}{$\mathrm{RI}=\mathbf{9 0 \%}$} & \multicolumn{2}{|c|}{$\mathrm{RI}=100 \%$} \\
\hline & $\begin{array}{c}\mathrm{T} 1 \\
(\mathrm{sec})\end{array}$ & $\gamma_{1}^{\mathrm{a}}$ & $\begin{array}{c}\text { T1 } \\
(\text { sec })\end{array}$ & $\mathbf{P S}^{\mathrm{b}}$ & $\begin{array}{c}\mathrm{T} 1 \\
(\mathrm{sec})\end{array}$ & $\mathbf{P S}^{\mathrm{b}}$ & $\begin{array}{c}\mathrm{T} 1 \\
(\mathrm{sec})\end{array}$ & $\mathbf{P S}^{\mathrm{b}}$ & $\begin{array}{c}\mathrm{T1} \\
(\mathrm{sec})\end{array}$ & $\mathbf{P S}^{\mathrm{b}}$ & $\begin{array}{c}\mathrm{T} 1 \\
(\mathrm{sec})\end{array}$ & $\mathbf{P S}^{\mathrm{b}}$ & $\begin{array}{c}\mathrm{T} 1 \\
(\mathrm{sec})\end{array}$ & $\mathbf{P S}^{\mathrm{b}}$ \\
\hline 3 -story & 0.44 & $76 \%$ & 0.51 & $14.2 \%$ & 0.50 & $12.8 \%$ & 0.50 & $11.7 \%$ & 0.49 & $10.6 \%$ & 0.55 & $24.1 \%$ & 0.54 & $22.1 \%$ \\
\hline 6 -story & 0.57 & $73 \%$ & 0.69 & $20.4 \%$ & 0.68 & $18.1 \%$ & 0.67 & $16.2 \%$ & 0.66 & $14.8 \%$ & 0.79 & $37.5 \%$ & 0.76 & $31.7 \%$ \\
\hline 9-story & 0.78 & $72 \%$ & 0.95 & $21.9 \%$ & 0.93 & $19.7 \%$ & 0.92 & $18.4 \%$ & 0.91 & $16.6 \%$ & 1.02 & $30.9 \%$ & 0.99 & $27.9 \%$ \\
\hline 12-story & 1.03 & $69 \%$ & 1.24 & $20.4 \%$ & 1.22 & $18.1 \%$ & 1.21 & $16.9 \%$ & 1.19 & $15.3 \%$ & 1.33 & $29.0 \%$ & 1.30 & $26.2 \%$ \\
\hline
\end{tabular}

${ }^{a} \gamma_{1}$ : Modal mass participation ratio of the first mode.

${ }^{b} \mathrm{PS}$ : Shifting period amount in percentage.

limitations in equivalent static analysis:

$$
\Delta_{\mathrm{NLTH}}<1.25 \Delta_{a},
$$

where, $\Delta_{\mathrm{NLTH}}$ is maximum displacement obtained from an NLTH analysis and $\Delta_{a}$ is maximum displacement obtained from the equivalent lateral force procedure. For certain structural models used in this research, the code drift limitations are the following:
$\frac{\Delta_{a}}{h_{u c}}=0.025$ for the 3 -story structures

$\frac{\Delta_{a}}{h_{u c}}=0.020$ for other structures

$$
\text { (6-, 9- and 12-story structures), }
$$

in which, $h_{u c}$ is the story height. 


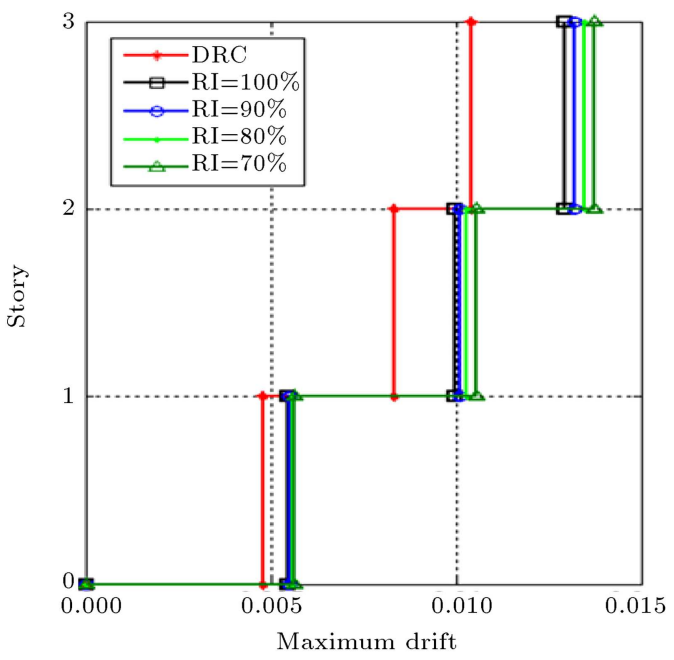

(a)

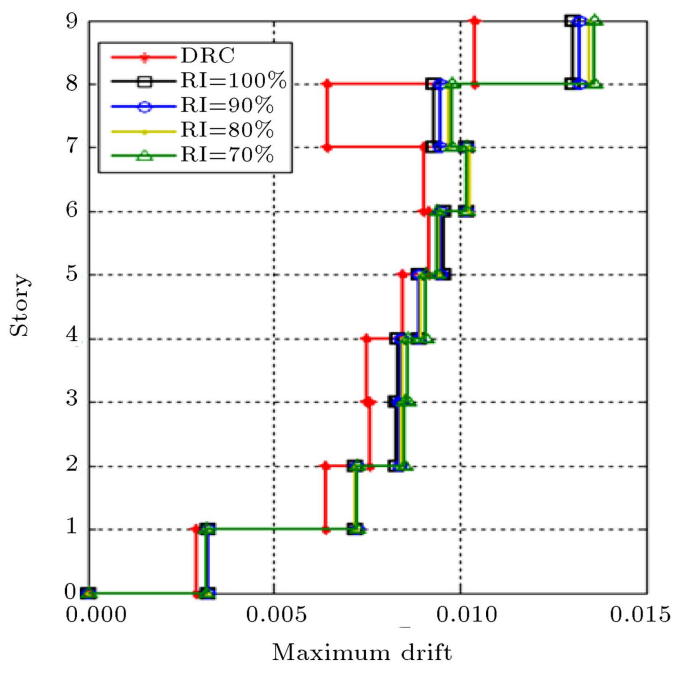

(c)

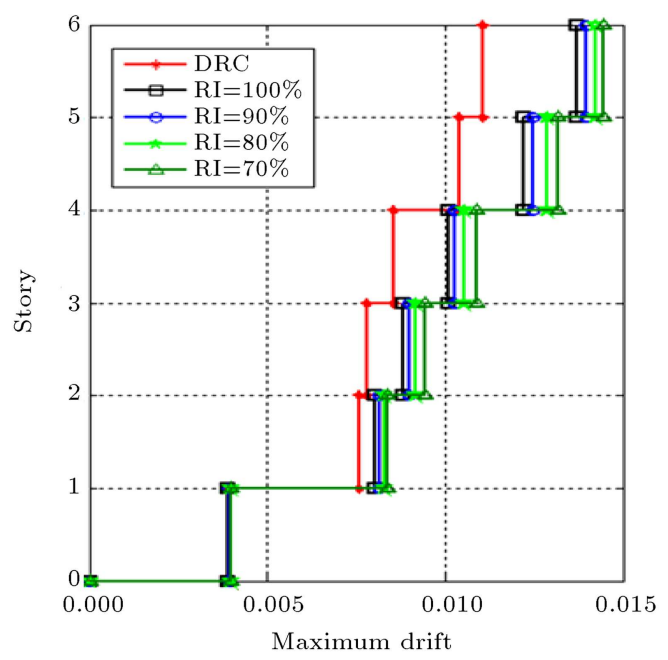

(b)

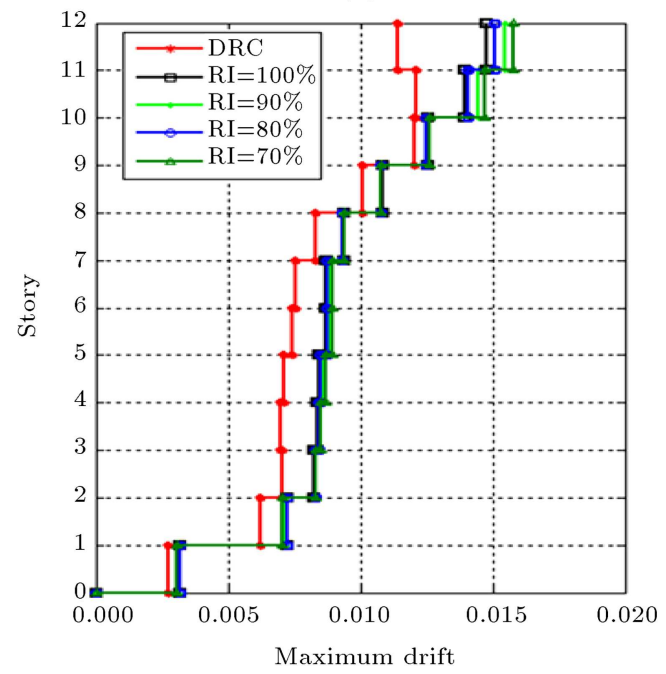

(d)

Figure 8. The maximum drifts for structural models with 5\% eccentricity in (a) 3-story, (b) 6-story, (c) 9-story, and (d) 12-story building models.

An extensive parametric study is performed in this regard, from which only the results of structural models with $5 \%$ eccentricity are presented here. In Figure 8, the maximum drifts for $x y$ direction (SRSS of $x$ and $y$ directions) are presented. The DRC index in this figure refers to conventional direct rigid beam-tocolumn connections and the percentage values refer to various assumed amounts of RI. Comparison of these results with those presented in Section 4.1 for the structural models equipped with the proposed semirigid steel-SMA connections demonstrate the dramatic decrease in force demand values. Based on the obtained results for other structural models with other mass eccentricities, the same results have been observed. It is important to notice that based on the authors' studies in similar structural models equipped with the proposed connections of Ma et al. [13], drift values are, in some cases, more than twice the allowable drift values of the code.

\subsection{Permanent displacement}

According to the obtained results with regard to the inter-story drifts, an important question to be answered is the condition of the structures after an earthquake. As discussed before, allowing the structures to experience the maximum code based story drifts is desirable if no considerable permanent displacement appears at the end of the earthquake episode. In case of satisfying both of the conditions, one could be assured of the acceptable performance of the structures equipped with the proposed connections with regard to both the force and displacement requirements. Therefore, an evaluation of the permanent story displacements of different structural models using NLTH analysis would be necessary. Figure 9 illustrates the residual displacements for the 12-story structural model.

According to Figure 9, the story permanent displacements in the 12-story structural model equipped with the proposed connections are less than those of 


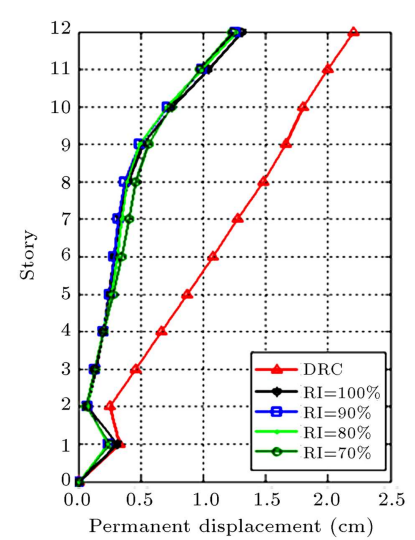

(a)

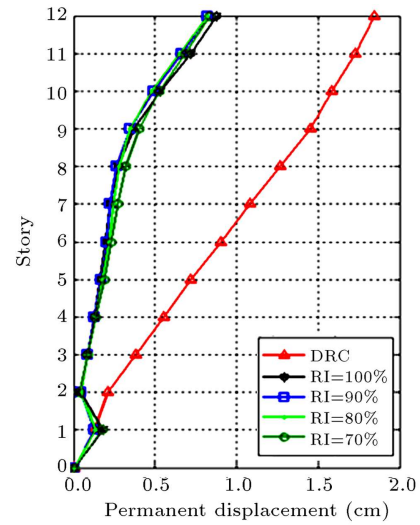

(b)

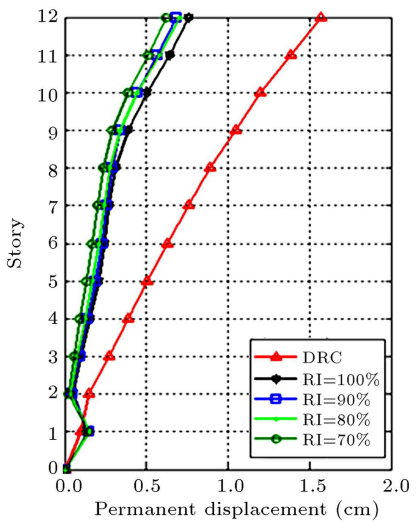

(c)

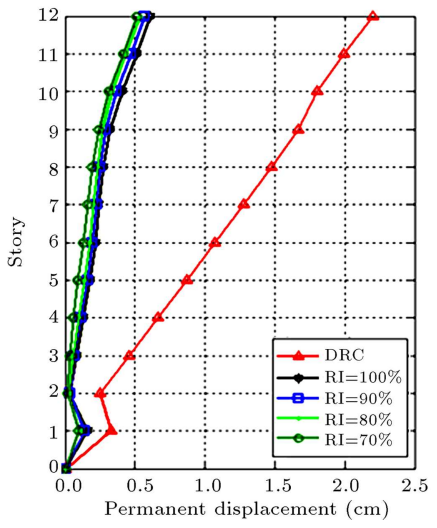

(d)

Figure 9. Permanent displacement of the 12-story buildings with (a) no eccentricity, (b) $5 \%$ eccentricity, (c) $10 \%$ eccentricity, and (d) $15 \%$ eccentricity.

the structural models having conventional connections for all considered eccentricities. Although not shown here, in 3- to 6-story structural models, the permanent displacement in both structural models with the conventional and proposed connections is negligible. In 12-story structural models equipped with the proposed connections, reducing the RI parameter from $100 \%$ to $70 \%$ leads to a decrease in the permanent displacements of different stories. In general, best results are gained for RIs equal to $80 \%$ and $90 \%$. In general, regarding the 12-story structural models, application of the proposed connections reduces the permanent displacements of all stories for the considered mass eccentricities.

\section{Conclusions}

- The obtained results indicate that the application of end-plate connections with parallel application of steel and SMA bolts has a significant effect in reducing the structural responses in comparison to the conventional direct rigid beam-to-column connections. In all structural models with different mass eccentricities, utilizing the proposed connections has a significant role in reducing the base shear force and flexural demands of beams according to the assumed features of the structural models.

- An increase in RI leads to an increase in the maximum base shear force. Another significant result is about the damage induced in beams by the use of the proposed connections. This damage is defined as the ratio of maximum rate of experienced curvature of each story's beams to the corresponding value for yield to occur, without considerable damages to columns. Higher RI values result in an increase in the induced curvatures of the beam ends and the obtained results indicate that its value should not be less than $70 \%$. Moreover, the values greater than $100 \%$ for RI lead to an interruption in the expected formation of hysteretic loops of SMA bolts, thus reducing the expected performance of the proposed connections.

- An increase in mass eccentricity not only reduces the performance of the proposed connections, but also increases the base shear forces in some cases in comparison to the structural models with conventional connections.

- The maximum inter-story drift limits of all the structural models according to ASCE-7 design code are satisfied using the proposed connection. Moreover, adequate reduction is observed in the maximum permanent displacement of different stories of structural models.

\section{References}

1. Kunnath, S.K. and Malley, J.O. "Advances in seismic design and evaluation of steel moment frames", recent findings from FEMA/SAC phase II project. $J$. of Structural Engineering (ASCE), 128(4), pp. 415-419 (2002).

2. Sabol, T.A. "An assessment of seismic design practice of steel structures in the United States since the Northridge earthquake", J. of The Structural Design of Tall and Special Buildings, 13(5), pp. 409-423 (2004).

3. Ricles, J.M., Fisher, J.W., Lu, L.W. and Kaufmann, E.J. "Development of improved welded moment connections for earthquake-resistant design", J. of Constructional Steel Research, 58(5-8), pp. 565-604 (2002).

4. Wang, W.D., Han, L.H. and Brian, U. "Experimental behaviour of steel reduced beam section to concretefilled circular hollow section column connections", $J$. of Constructional Steel Research, 64(5), pp. 493-504 (2008).

5. Kim, Y.J. and Oh, S.H. "Effect of the moment transfer efficiency of a beam web on deformation capacity at box column-to-H beam connections", J. of Constructional Steel Research, 63(1), pp. 24-36 (2007). 
6. Mander, T.J. Rodgers, G.W., Chase, J.G., Mander, J.B., MacRae, G.A. and Dhakal, R.P. "Damage avoidance design steel beam-column moment connection using high-force-to-volume dissipators", J. of Structural Engineering (ASCE), 135(11), pp. 1390-1397 (2009).

7. Sumner, E.A. and Murray, T.M. "Behavior of extended end-plate moment connections subject to cyclic loading", J. of Structural Engineering (ASCE), 128(4), pp. 501-508 (2002),

8. Song, G., Ma, N. and Li, H.-N. "Applications of shape memory alloys in civil structures", $J$. of Engineering Structures, 28(9), pp. 1266-1274 (2006).

9. Dolce, M., Cardone, D. and Marnetto, R. "Implementation and testing of passive control devices based on shape memory alloys", J. of Earthquake Engineering and Structural Dynamics, 29, pp. 945-68 (2000).

10. Wilde, K., Gardoni, P. and Fujino, Y. "Base isolation system with shape memory alloy devices for elevated highway bridges", J. of Engineering Structures, 22(3), pp. 222-9 (2000).

11. Czaderski, C., Hahnebach, B. and Motavalli, M. "RC beam with variable stiffness and strength", $J$. of Construction and Building Materials, 20(9), pp. 82433 (2006).

12. Rofooei, F.R. and Farhidzadeh, A. "Investigation on the seismic behavior of steel MRF with shape memory alloy equipped connection", The 12th East Asia Conference on Structural Engineering and Construction, Procedia Engineering, 14, pp. 3325-3330 (2011).

13. Ma, H., Cho, Ch. and Wilkinson, T. "A numerical study on bolted end-plate connection using shape memory alloys", J. of Materials and Structures, 41, pp. 1419-1426 (2008).

14. Abolmaalia, A., Treadway, J., Aswath, P., Luc, F.K. and McCarthy, E. "Hysteresis behavior of t-stub connections with superelastic shape memory fasteners", J. of Constructional Steel Research, 62, pp. 831-838 (2006).

15. Ocel, J., DesRoches, R., Leon, R.T., et al. "Steel beamcolumn connections using shape memory alloys", $J$. of Structural Engineering (ASCE), 130(5), pp. 732-40 (2004).

16. Ma, H., Wilkinson, T. and Cho, Ch. "Feasibility study on a self-centering beam-to-column connection by using the superelastic behavior of SMAs", J. of Smart Materials and Structures, 16, pp. 1555-1563 (2007).

17. Janke, L., Czaderski, C., Motavalli, M. and Ruth, J. "Application of shape memory alloys in civil engineering structures-Overview, limits and new ideas", J. of Material and Structures, 38, pp. 578-592 (2005).

18. DesRoches, R., McCormick, J. and Delemont, M. "Cyclic properties of superelastic shape memory alloy wires and bars", J. of Structural Engineering (ASCE), 130(1), pp. 38-46 (2004).

19. Dolce, M. and Cardone, D. "Mechanical behaviour of shape memory alloys for seismic applications 2 . Austenite NiTi wires subjected to tension", Int. J. of Mechanical Sciences, 43(11), pp. 2657-2677 (2001).

20. Motahari, S.A., Ghassemieh, M. and Abolmaali, S.A. "Implementation of shape memory alloy dampers for passive control of structures subjected to seismic excitations", J. of Constructional Steel Research, 63, pp. 1570-1579 (2007).

21. McCormick, J., DesRoches, R., Fugazza, D. and Auricchio, F. "Seismic vibration control using superelastic shape memory alloys", J. of Engineering Materials and Technology, 128, pp. 294-301 (2006).

22. DesRoches, R. and Smith, B. "Shape memory alloys in seismic resistant design and retrofit: a critical review of their potential and limitations", J. of Earthquake Engineering, 7(3), pp. 1-15 (2003).

23. Wang, X.M., Wang, Y.F., Lu, Z.Z., Deng, C.H. and Yue, Z.F. "An experimental study of the superelastic behavior in NiTi shape memory alloys under biaxial proportional and non-proportional cyclic loadings", $J$. of Mechanics of Materials, 42(3), pp. 365-373 (2010).

24. Auricchio, F., Fugazza, D. and DesRoches, R. "Numerical and experimental evaluation of the damping properties of shape-memory alloys", J. of Engineering Materials and Technology, 128, pp. 313-319 (2006).

25. Yadegari Farzaneh, A. "Application of different arrangement of shape memory alloys equipped connections to improve the seismic behavior of steel MRFs", MSc Thesis (in Persian), Building and Housing Research Center, Tehran, Iran (2012).

\section{Biographies}

Fayaz Rahimzadeh Rofooei joined Sharif University of Technology right after finishing his PhD studies in Structural Control in 1992 at Rensselaer Polytechnic Institute, New York, US. He has been active in Civil Engineering Department ever since, holding different managerial positions. His field of research includes earthquake engineering, passive and active structural control, and structural rehabilitation.

Abbas Yadegari Farzaneh is a BSc graduate of BuAli Sina University in Civil Engineering and an MSc graduate of BHRC in Earthquake Engineering. He has conducted much research on the passive vibration control of structural systems. He has designed many structures equipped with seismic friction damping systems of which some have been constructed and others are under construction. 